УДК 33

\title{
СПОСОБЫ ОЦЕНКИ ЭФФЕКТИВНОСТИ ФИНАНСОВОЙ МОДЕЛИ УПРАВЛЕНИЯ РИСКАМИ НА ПРЕДПРИЯТИИ
}

\author{
Блинова Елена Дмитриевна \\ Научный руководитель: Филиппов Сергей Дмитриевич \\ к.ф. - м.н., доцент \\ ФБОУ ВО «Уральский государственный экономический университет»
}

Аннотация: Термин «эффективность» происходит от латинского слова «effectus» - действие, эффект. Согласно экономическому словарю эффективность - это достижение максимального результата с минимальными затратами [1]. Такая трактовка впервые появилась в экономической теории в 1911 году благодаря работе Г. Эмерсона «12 принципов производительности», в которой был введён термин «эффективность труда» как «максимально выгодное соотношение между совокупными затратами и экономическими результатами» [2]. Однако вопрос о том, что понимать под эффективностью управления рисками на предприятии и как правильно её оценивать, актуален и по сей день. В рамках корпоративного управления до сих пор нет единого мнения, как соотносить понятия «эффект», «эффективность» и «экономичность», а также нет универсальной системы показателей оценки эффективности [3]. В связи с чем авторы предлагают изучить современные подходы к оценке эффективности рискменеджмента.

Ключевые слова: эффективность, риск-менеджмент, управление рисками, методы управления рисками, оценка эффективности риск-менеджмента

\section{METHODS FOR ASSESSING THE EFFICIENCY OF THE FINANCIAL RISK MANAGEMENT MODEL IN THE ENTERPRISE}

\section{Blinova Elena Dmitrievna Scientific advisor: Filippov Sergei Dmitrievich}

\begin{abstract}
The term "efficiency" comes from the Latin word "effectus" - action, effect. According to the economic dictionary, efficiency is achieving the maximum result with the minimum cost [1]. This interpretation first appeared in economic theory in 1911 thanks to the work of G. Emerson "12 principles of productivity", in which the
\end{abstract}


term "labor efficiency" was introduced as "the most beneficial ratio between total costs and economic results" [2]. However, the question of what is meant by the effectiveness of risk management at an enterprise and how to properly assess it is still relevant today. Within the framework of corporate governance, there is still no consensus on how to correlate the concepts of «effect», «efficiency», and «economy», and there is also no universal system of indicators for assessing efficiency [3]. In this connection, the authors propose to study modern approaches to evaluate the effectiveness of risk management.

Key words: efficiency, risk management, risk management, risk management methods, assessment of the effectiveness of risk management

Согласно рекомендациям Р 50.1.093-2014 [4] эффективными считаются такие мероприятия по управлению рисками, которые обеспечивают снижение вероятности наступления риска до допустимого уровня (в пределах риск-аппетита предприятия) при минимальных затратах. Однако в отношении определённых рисков (риск безопасности жизни и здоровья людей, экологический риск, репутационный риск) эффективными будут считаться такие методы управления, которые помогут в достижении поставленных предприятием целей вне зависимости от затрат. Следовательно, в качестве критериев эффективности рискменеджмента выступают:

1. Степень воздействия на вероятность рискового события.

$k_{1}=R_{\text {int }}-R_{\text {res }}$,

где $R_{\text {int }}-$ присущий риск;

$R_{\text {res }}$ - остаточный риск.

2. Степень воздействия на последствия рискового события.

$k_{2}=D_{\text {int }}-D_{\text {res }}$,

где $\quad D_{\text {int }}-$ присущий уровень последствий;

$D_{\text {res }}$ - остаточный уровень последствий.

3. Соотношения затрат на применение мер с ожидаемым эффектом.

$k_{3}=\frac{\mathrm{C}}{R_{\text {int }}-R_{\text {res }}}$,

где $\mathrm{C}$ - сумма затрат на мероприятия по управлению риском.

4. Соотношения остаточного и допустимого риска.

$k_{4}=\frac{R_{\text {res }}}{R_{\text {tol }}}$,

где $R_{\text {tol }}-$ допустимый риск.

5. Соотношение эффекта от применения мер с упущенной выгодой.

$k_{5}=\frac{B_{l}}{\Delta R}$ 
где $\quad B_{l}-$ размер упущенной выгоды;

$\Delta R$ - эффект воздействия на риск.

6. Соотношение эффекта от применения мер с уровнем рисков, возникающих вследствие данного воздействия.

$$
k_{5}=\frac{R_{a d d}}{\Delta R},
$$

где $R_{a d d}-$ размер негативных побочных эффектов от воздействия на риск.

Приведённые соотношения являются основными, но не единственными из тех, которыми предприятие может пользоваться для оценки эффективности предлагаемых мероприятий по управлению рисками на этапе их обработки.

Большинство исследований [2, 5-16] в области оценки эффективности процесса управления рисками основаны на понятии «экономической эффективности». Таким образом, эффективность риск-менеджмента представлена как соотношение результата процесса управления рисками с затраченными на него средствами и оценивается непосредственно после проведения мероприятий по обработке рисков.

Например, Макарова В. А. отмечает, что эффективность применяемых методов воздействия на риск необходимо рассчитывать по методике Парето, предварительно оценив прирост целевых показателей предприятия после внедрения или модернизации риск-менеджмента [11]. Следовательно, в первую очередь необходимо провести расчёт прироста EBITDA, выручки, чистых активов и долгосрочной задолженности. Если будет получен положительный результат, значит проведённые мероприятия были эффективны. Тогда в целях количественной оценки эффективности риск-менеджмента следует воспользоваться формулой по Парето:

$E_{p}=\frac{R_{p}}{C_{p}}$

где $E_{p}$-эффективность управления рисками;

$R_{p}$ - результат управления рисками;

$C_{p}$ - сумма затрат всех расходуемых ресурсов.

Как можно видеть, $R_{p}$ и есть количественный результат прироста основных показателей деятельности предприятия: EBITDA, выручки, чистых активов и долгосрочной задолженности. $C_{p}$ следует рассчитать по следующей формуле:

$C_{p}=\left(\sum_{i=1}^{N} L_{f_{i}}+\sum_{i=1}^{N} H_{f_{i}}\right)+\left(\sum_{j=1}^{K} L_{f_{j}}+\sum_{j=1}^{K} H_{f_{j}}\right)$,

где $N$-количество идентифицированных рисков; 
$L_{f_{i}}$ - фактические убытки от появления -го идентифицированного риска;

$H_{f_{i}}$ - фактические расходы на обработку -го идентифицированного риска;

$K$ - количество неидентифицированных рисков;

$L_{f_{j}}$ - фактические убытки от появления -го неидентифицированного риска;

$H_{f_{j}}$ - фактические расходы на обработку -го неидентифицированного риска.

Кроме того, Макаровой В. А. предложена регрессионная модель для описания финансового эффекта от внедрения (модернизации) риск-менеджмента:

$y=$ const $+k_{c} f_{c}+k_{e} f_{e}+k_{a} f_{a}$,

где $y$ - прирост EBITDA после внедрения (модернизации) рискменеджмента;

const - EBITDA предприятия при нулевых факторах регрессии;

$f_{c}$ - рост затрат на риск-менеджмент;

$f_{e}$ - экономическая эффективность риск-менеджмента;

$f_{a}$ - изменение чистых активов предприятия;

$k_{c}, k_{e}, k_{a}-$ коэффициенты регрессии.

Подобный «затратный» подход предложен семейством Рубиных [17]:

$\ni_{\mathrm{o}}=\frac{\Pi}{3_{\text {c.y. }}+3_{\text {o.y. }}}$

где $Э_{\text {о }}$ - общая эффективность управления рисками;

П - результирующая прибыль предприятия;

$3_{\text {c.y. }}$ - затраты субъектов управления;

$3_{\text {о.у. }}$ - затраты объектов управления.

Анесяц С. А. в своей работе [5] так же делает акцент на соотношении величины возможных эффектов и стоимости проводимых работ:

$Z=\Delta P-C$,

где $Z$ - экономический эффект от мероприятий по управлению рисками;

$\Delta P$ - изменение величины ожидаемых последствий риска;

$C$ - совокупная стоимость мероприятий.

При этом $\Delta P$ является разностью между ожидаемыми и фактическими убытками, а $C$ рассчитывается по следующей формуле:

$C=\sum_{i=1}^{N}\left(C_{i} \times A_{i}\right)$,

где $N$ - количество запланированных мероприятий по управлению рисками;

$C_{i}$ - стоимость проведения -го мероприятия;

$A_{i}$ - альтернативная стоимость проведения -го мероприятия. 
В работе Гостениной В. В. [7] предложен как «затратный» подход, так и способ измерения эффективности риск-менеджмента через оценку потерь.

ЭРМ $_{\text {затратный }}=\frac{\mathrm{CB}-3}{3}$,

где ЭРМ $_{\text {затратный }}$ - эффективность риск-менеджмента по затратному подходу;

СВ - совокупная выгода;

3 - затраты на проведение мероприятий.

ЭРМ ${ }_{\text {потери }}=\frac{\Pi_{\mathrm{p}} \times \mathrm{P}_{\text {пр }}}{3_{\mathrm{p}}+\Pi_{\Pi}+\Pi_{\mathrm{p}} \times \mathrm{P}_{3 \mathrm{p}}}$,

где ЭРМ $_{\text {потери }}-$ эффективность риск-менеджмента через оценку потерь;

$\Pi_{p}$ - затраты в случае возникновения риска;

$\mathrm{P}_{\text {пр }}$ - условная вероятность увеличения затрат от воздействия риска;

$3_{\mathrm{p}}$ - затраты на проведение мероприятий;

$\Pi_{\Pi}-$ потери после проведения мероприятий;

$\mathrm{P}_{\text {зр }}$ - условная вероятность не обнаружения риска.

$\Pi_{p}=\Pi_{\text {н.сд. }}+\Pi_{\text {с.сд. }}+\Pi_{\text {заб.пр. }}+\Pi_{\text {эк.шп., }}$,

где $\Pi_{\text {н.сд. }}-$ затраты, связанные с незаключенными сделками;

$\Pi_{\text {с.сд. }}-$ затраты, вызванные сорванными контрактами;

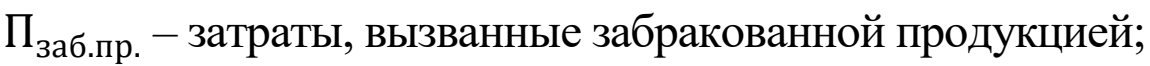

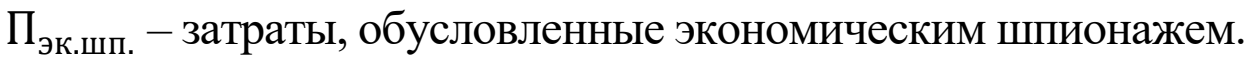

$3_{\mathrm{p}}=3_{\text {с.ин. }}+3_{\text {ан.ин. }}+3_{\text {мин. }}+3_{\text {з.пл. }}$,

где $3_{\text {с.ин. }}-$ затраты на сбор информации;

$3_{\text {ан.ин. }}$ - затраты на анализ информации;

$3_{\text {мин. }}$ - затраты на предотвращение потерь;

$3_{\text {з.пл. }}$ - ФОТ сотрудников системы риск-менеджмента.

Работы Барашьян В. Ю. [6] и Оганисян Л. А. [18] основаны на COSO ERM [1], согласно которой критериями эффективности выступают 8 компонентов:

1. Степень и качество восприятия сотрудниками предприятия рисков.

2. Цели выбраны, сформированы, соответствуют миссии и риск-аппетиту.

3. Определены внутренние и внешние события. Разделены на риски и возможности. Возможности учтены при формировании и постановке целей.

4. Риски оценены по вероятности возникновения и воздействию.

5. Произведён выбор метода реагирования на риск: уклонение от риска, принятие, сокращение или перераспределение риска - с учётом допустимого уровня риска и риск-аппетита предприятия в целом. 
6. Процедуры обеспечивают эффективное и своевременное реагирование.

7. Осуществляется эффективный разносторонний обмен информацией.

8. Процесс управления рисками отслеживается и поддаётся корректировке.

Таким образом, эффективной будет считаться такая модель управления рисками, в результате применения которой отсутствуют значительные недостатки по каждому из восьми компонентов, а риск по ним находится в пределах рискаппетита предприятия. Иными словами по каждому из восьми компонентов должно выполняться следующее неравенство:

$\Delta R F \geq \triangle R P \geq E x P \geq E x F$,

где $\quad \Delta R F$ - сумма изменений реализованных рисков;

$\Delta R P$ - сумма изменений запланированных рисков;

$E x P$ - сумма запланированных затрат;

$E x F$ - сумма фактически понесённых затрат.

Необходимо отметить, что COSO ERM претерпела ряд изменений [19]. В частности, вместо восьми компонентов теперь рассматриваются всего пять:

1. Выявлены все риски, связанные с достижением стратегических и бизнес-целей. Сформирована общая база. Проставлена актуальность каждого риска. Риски структурированы и определены на всех уровнях и функциях.

2. Риски оценены по воздействию и вероятности. Описаны риск-факторы и последствия наступления каждого риска. При количественной и (или) качественной оценке рисков оценены такие виды рисков, как присущий, целевой остаточный и фактический остаточный. Для графической визуализации построена карта рисков. Принят во внимание и снижен эффект предвзятости.

3. Учтён риск-аппетит. Приоритеты рисков выставлены по разработанным на предприятии критериям (например, адаптивность к риску, сложность, скорость воздействия, устойчивость влияния, восстановление после реализации риска).

4. Выделены 5 стратегий: принятие, избегание, добор, снижение и передача риска. Выбор стратегии основан на оценке условий ведения бизнеса, соотношении выгод и затрат, обязательств и ожиданий, риск-аппетита и существенности риска.

5. Комплексный взгляд на риски. Определяется разница между остаточным профилем риска и установленным риск-аппетитом. Выбран способ интеграции:

- минимальная (фокус на существенные рисковые события);

- ограниченная (фокус на риски, структурированные по категориям);

- частичная (фокус на риски, связанные с достижением бизнес-цели); 
- полная интеграция (комплексный взгляд на риски).

При изучении способов оценки эффективности риск-менеджмента нельзя не рассмотреть работы таких авторов, как Корниенко О.Ю. и Макаровой В.А. [10], Михева П.С. [13] (основана на COSO ERM) и Филотенковой В. В. [16], в которых приведён ещё один критерий экономической эффективности - NPV :

$\mathrm{CУP}_{\text {эффект }}=N P V^{\prime}-N P V$,

где СУР эффект - эффективность системы управления рисками;

$N P V^{\prime}$ - чистая приведённая стоимость после внедрения риск-менеджмента;

$N P V$ - чистая приведённая стоимость до внедрения риск-менеджмента.

Кроме того, Корниенко О.Ю. и Макарова В.А. предлагают использовать вместо $N P V$ показатель скорректированной чистой приведённой стоимости FNPV:

$$
F N P V=\sum_{t=1}^{n} \frac{F C F_{t}}{(1+k)^{t}}-I_{0},
$$

где $F C F_{t}-$ достоверный ожидаемый денежный поток за период $t$;

$k$ - ставка дисконтирования;

$I_{0}$ - исходные инвестиции.

$F C F_{t}=\alpha_{t} \times P C F_{t}$,

где $\alpha_{t}-$ коэффициент надёжности получения ожидаемых денежных потоков;

$P C F_{t}$ - ожидаемая стоимость чистых денежных потоков в период $t$.

Филотенкова В. В. совместно с Демиденко Д. С. [8] предложили ещё один способ выбора экономически эффективных методов управления рисками, применяя матрицу рисков. Посредством математического представления постановки задачи нахождения оптимальной траектории авторы вычислили, что выгоднее выбирать один из двух путей минимизации вероятности риска: методы, при которых первоначально уменьшиться вероятность рисков с максимума до минимума, а уже потом уменьшится размер самих потерь; методы, при которых вероятность рисковых событий и размер потерь необходимо снижать друг за другом поэтапно.

Ещё одним критерием эффективности риск-менеджмента может выступать соотношение риска и доходности [20]. По мнению Муравьёвой Н.Н. и Блиновой Т.К. [14], помимо оптимального соотношения риска и доходности они рассматривают в качестве основных критериев также результативность (т.е. прирост прибыли до налогообложения) и общую экономичность предприятия.

$$
\frac{\text { Риск }}{\text { Доходность }}=\frac{\text { СВФР }}{\Phi У}
$$


где СВФР - сила воздействия финансового рычага;

ФУ - финансовая устойчивость.

$\mathrm{CВФР}=\frac{\Delta ч \Pi}{\Delta \Pi_{\text {пр }}}$,

где $\quad \Delta$ ЧП - темп изменения чистой прибыли, \%;

$\Delta \Pi_{\text {пр }}-$ темп изменения прибыли от продаж, \%.

СВФР необходимо минимизировать при заданном уровне рентабельности.

$\Phi \mathrm{Y}=\frac{3 \mathrm{~K}}{\mathrm{CK}}$

где $3 К-$ заёмный капитал;

СК - собственный капитал.

ФУ необходимо минимизировать при уровне дифференциала больше 5 \%:

$Э Ф \mathrm{P}=\left[\left(1-\mathrm{C}_{\mathrm{H \Pi}}\right) \times\left(Э \mathrm{P}_{\mathrm{a}}-\mathrm{C}_{\mathrm{p}}\right)-\mathrm{C}_{\Pi}\right] \times \frac{3 \mathrm{KK}}{\mathrm{CK}}$

где ЭФР - эффект финансового рычага;

$\mathrm{C}_{\text {нп }}-$ ставка налога на прибыль;

ЭР $\mathrm{a}_{\mathrm{a}}$ - экономическая рентабельность активов;

СП

СП п - ставка процентов по капиталу, относимая на прибыль

$\left({ }_{\mathrm{a}}-\mathrm{C} \Pi_{\mathrm{p}}\right)-\mathrm{C \Pi}_{\Pi}-$ дифференциал.

Экономичность общая $=\frac{\text { Себестоимость }}{\text { Активы }} \overline{\overline{И Л и ~}} \frac{\text { Себестоимость }}{\text { Выручка }}$,

Другим способом оценки эффективности является принцип «шансо-риска», описанный в работе Ениной Е. П. [9]:

$E F F=\frac{\text { Chance }- \text { Risk }}{E}-1$,

где Chance - шанс прибыли, который включает в себя оценку факта выполнения и количества текущих операций, ставки комиссии и частоты операций;

Risk - риск ущерба;

$E$ - затраты по поддержанию работоспособности системы рискменеджмента (факт и объём затрат, количество текущих вложений и частота их проведения).

Итак, мы рассмотрели основные современные подходы к оценке экономической эффективности риск-менеджмента предприятия. Теперь рассмотрим методологии оценки процессной, операционной, рыночной, стратегической и комплексной эффективности риск-менеджмента. 
Процессная эффективность основана на системе KPI, которая представлена в работе Корниенко О. Ю., Макаровой В. А. [10] и Новикова А. А. [2121].

Корниенко О. Ю. и Макарова В. А. рассматривают в качестве критериев KPI:

1. Эффективность методов идентификации рисков

$K P I_{1}=\frac{n_{2}}{n_{1}+n_{2}} \times d\left(i n f_{1} ; i n f_{2} ; i n f_{3} ; i n f_{4}\right)$,

где $n_{1}$ - число проявившихся потенциальных рисков;

$n_{2}$ - число непроявившихся потенциальных рисков;

$d\left(i n f_{1} ; i n f_{2} ; i n f_{3} ; i n f_{4}\right)$ - функция, отражающая степень чёткости и достоверности выполнения идентификации потенциальных рисков.

2. Показатель роста рентабельности предприятия

$K P I_{2}=R O E_{i}-E R R_{i-1}$,

где $R O E_{i}$ - рентабельность предприятия в -ый период;

$E R R_{i-1}$ - ожидаемый уровень нормы доходности в предыдущем периоде;

$E R R=\sum_{j=1}^{n}\left(I R R_{j} \times \rho_{j}\right)$,

где $I R R_{j}-$ внутренняя норма доходности -го события;

$\rho_{j}-$ рентабельность -го события.

3. Доля затрат на управление рисками в чистом денежном потоке

$K P I_{3}=\frac{\sum_{i=1}^{n} C_{r_{i}}}{N C F}$,

где $C_{r_{i}}-$ затраты на управление -ым риском;

$N C F$ - чистый денежный поток.

4. Индикатор целесообразности управления -ым риском

$K P I_{4}=C_{r_{i}}-L_{i}$,

где $\quad L_{i}-$ потенциальные убытки от реализации -го риска.

В свою очередь, Новиков А. А. выделяет следующие KPI критерии:

1. Восьми факторная модель M-score

$\mathrm{M}-$ score $=-4.48+0.92 \times D S R I+0.528 \times G M I+0.404 \times A Q I+0.892 \times$

$S G I+0.115 \times D E P I-0.172 \times S G A I+4.679 \times T A T A-0.327 \times L V G I$,

где $D S R I-$ индекс дневных продаж в дебиторской задолженности;

GMI - индекс рентабельности продаж по валовой прибыли;

$A Q I$ - индекс качества активов;

$S G I$ - индекс роста выручки;

$D E P I$ - темп роста доли амортизационных расходов в стоимости основных средств предприятия; 
$S G A I$ - индекс коммерческих и управленческих расходов;

TAT A - суммарные начисления к суммарным активам;

LV GI - индекс коэффициента финансовой зависимости.

2. Экономическая эффективность риск-менеджмента

$E_{r m}=\frac{R_{r m}}{C_{r m}}$

где $R_{r m}$ - прирост выручки после внедрения (модернизации) рискменеджмента;

$C_{r m}$ - затраты на внедрение (модернизацию) риск-менеджмента.

3. Относительное отклонение фактической добавленной стоимости

$\triangle S V A=\frac{S V A_{n}}{S V A_{r}}$

где $S V A_{n}$ - фактическая стоимость предприятия;

$S V A_{r}$ - плановая (под риском) стоимость предприятия.

4. Относительное отклонение фактической экономической добавленной стоимости предприятия

$\triangle E V A=\frac{E V A_{n}}{E V A_{r}}$,

где $E V A_{n}-$ фактическая экономическая добавленная стоимость;

$E V A_{r}$ - плановая (под риском) экономическая добавленная стоимость.

5. Относительное отклонение прибыли

$\triangle R O E=\frac{R O E_{n}}{R O E_{r}} \overline{\overline{и л и}} \frac{R O E_{n}}{R A R O C}$,

где $R O E_{n}-$ фактическая рентабельность собственного капитала;

$R O E_{r}$ - плановая (под риском) рентабельность предприятия;

$R A R O C$ - рентабельность, скорректированная на риск.

Операционная эффективность основана на методе рейтинговой оценки, который также применяется в методологии COSO ERM. В работе Корниенко О.Ю. и Макаровой В. А. [10] проверяется выполнение двух критериев:

1. Методика идентификации рисков.

○ Применяются качественные и количественные методы или нет.

○ Всем ли сотрудниками понятны критерии оценки риска, сильные и слабые стороны систем и методов измерения рисков.

2. Интеграция управления рисками в бизнес-процессы.

○ Больше ли 90\% бизнес-целей отображены в стратегии СУР.

○ Всегда ли СУР участвует в разработке бизнес-стратегий.

○ Больше ли $80 \%$ драйверов стоимости учитывают её с учётом риска.

○ Является ли качество СУР конкурентным преимуществом. 
○ Постоянно ли пересматривается стратегия риск-менеджмента.

○ Регулярно ли она обсуждается.

○ Постоянно ли пересматривается риск-аппетит Советом директоров.

○ Меньше ли $40 \%$ случаев неудавшихся бизнес-стратегий являются результатом мягких мер по управлению рисками.

○ Составляет ли менее $40 \%$ доля несвоевременных вмешательств.

○ Составляет ли менее $40 \%$ доля негативных новостей в СМИ.

○ Имеют ли менеджеры опыт во всех областях деятельности предприятия.

○ Несут ли все владельцы рисков персональную ответственность.

○ Является ли модель управления рисками стандартизированной.

○ Составляет ли менее 95\% доля проблем, связанных с неправильным комплаенсом, в общем числе раз предотвращения всех правовых проблем.

○ Независимы ли оценка и мониторинг рисков.

○ Чётко ли определены лимиты риска.

○ Меньше ли 95\% доля случаев превышения рисков над риск-аппетитом в общем числе случаев предотвращения превышения уровня риск-аппетита.

○ Составляет ли менее 95\% доля финансовых потерь, связанных с неправильным комплаенсом, в общем числе случаев предотвращения потерь.

○ Регулируется ли СУР после реализации каждого рискового события.

○ Снижается ли число несчастных случаев при ЧС от периода к периоду.

○ Постоянно ли проводится ретроспективный анализ.

○ Существует ли на предприятии система раннего предупреждения.

Необходимо отметить, что значимость применения предприятием как количественных, так и качественных методов также находит отражение в работе Сафоновой М. Ф. и Резниченко Д. С. [2221]. Поэтому Макаровой В. А. предложена количественная интерпретация рейтинговой оценки рыночной эффективности [12]:

$$
R=0.12 \times k_{1}+0.1 \times k_{2}+0.11 \times k_{3}+0.1 \times k_{4}+0.11 \times k_{5}+0.14 \times
$$
$k_{6}+0.12 \times k_{7}+0.12 \times k_{8}+0.08 \times k_{9}$,

где $\quad k_{1}-$ коэффициент концентрации и индекс Херфиндаля-Хиршмана;

$k_{2}$ - рентабельность выше средней по отрасли;

$k_{3}-W A C C$ предприятия ниже среднего значения по отрасли;

$k_{4}$ - наличие информации в СМИ об успешном внедрении СУР (прессрелизы об успешном внедрении - 1 балл; наличие информации о внедрении - 2 балла; отсутствует положительная информация - 3 балла);

$k_{5}$ - коэффициент покрытия процентов больше 1 ; 
$k_{6}$ - коэффициент финансовой безопасности меньше 3;

$k_{7}-$ коэффициент текущей ликвидности больше 1 ;

$k_{8}$ - особое отношение предприятия к его ключевым рискам (разработаны отдельные рекомендации по каждому ключевому риску - 1 балл; ограниченный перечень методов - 2 балла; отсутствует положительная информация - 3 балла);

$k_{9}$ - реализация СУР строго в соответствии с выбранным стандартом (все разделы изучены и адаптированы - 1 балл; ряд положений используется формально - 2 балла; формальное соблюдение или несоблюдение стандарта - 3 балла).

Оценка стратегической эффективности представлена в работе Кочеткова В. В. [3], Корниенко О. Ю. и Макаровой В. А. [10] в рамках стоимостной модели.

Кочетков В.В. рассматривает критериальный подход к оценке стратегической эффективности, отмечая значимость таких показателей, как:

2. Акционирование предприятия:

○ размер доли акционеров и инвесторов;

○ размер доли государства;

○ размер доли иностранного капитала;

○ размер и структура капитала предприятия;

○ виды акций, их номинальная цена и количество;

○ тип владения акциями предприятия.

3. Расширение деятельности предприятия (осуществление операций по приобретению, слиянию, поглощению, создание стратегических альянсов).

4. Общая характеристика предприятия:

○ направленность финансово-хозяйственной деятельности (ФХД);

○ организационно-правовая форма;

○ организационная структура;

○ структура системы стратегического управления;

○ масштабы управления деятельностью предприятия.

5. Общая характеристика ФХД предприятия:

○ инвестиционная активность;

○ инвестиционная привлекательность;

○ реальное финансовое состояние предприятия.

6. Система мотивации на предприятии (наличие).

7. Показатели влияния предприятия на общество в целом:

○ отношения с властями; 
○ влияние на местную и национальную экономику;

○ репутация предприятия.

Согласно подходу Корниенко О. Ю. и Макаровой В. А. модель управления рисками на предприятии будет считаться стратегически эффективной, если:

$$
\Delta B V=B V_{n+1}-\text { Value }_{V A R} \geq 0,
$$

где $B V_{n+1}-$ балансовая стоимость собственного капитала предприятия;

Value $_{V A R}$ - стоимость предприятия под риском по формуле A. Damodaran:

$$
\text { Value }_{V A R}=\sum_{i=1}^{m}\left(1-\alpha \times \sigma_{i}+\beta_{i}\right) \times\left(C_{0}+\sum_{t=1}^{n} \frac{E V A_{t, a}+E V A_{t, f p}}{\left(1+k_{c}\right)^{t}}\right),
$$

где $\quad \alpha$ - пороговое значение вероятности (например, при 5\% вероятности реализации рисковых событий на предприятии $\alpha=1.645)$;

$\sigma_{i}$ - стандартное отклонение доходности -го бизнес-процесса предприятия;

$\beta_{i}$ - среднее значение доходности -го бизнес-процесса предприятия;

$m$ - количество бизнес-процессов предприятия;

$C_{0}$ - капитал, инвестированный в активы;

$E V A_{t, a}-$ экономическая стоимость, добавленная активами;

$E V A_{t, f p}$ - ожидаемая экономическая стоимость, добавленная инвестициями;

$k_{c}$ - стоимость капитала предприятия;

$n$ - горизонт планирования.

Таким образом, рассмотрев подходы к оценке экономической, процессной, операционной, рыночной и стратегической эффективности модели управления рисками, мы получаем комплексную оценку, представленную в Таблице 1.

Таблица 1

Комплексная оценка эффективности риск-менеджмента [10]

\begin{tabular}{|l|c|c|c|c|}
\hline \multicolumn{1}{|c|}{ Вид эффективности } & Отлично & Хорошо & Удовл. & Неуд. \\
\hline Экономическая & 1 & 2 & 3 & 4 \\
\hline Процессная & 1 & 2 & 3 & 4 \\
\hline Операционная & 1 & 2 & 3 & 4 \\
\hline Рыночная & 1 & 2 & 3 & 4 \\
\hline Стратегическая & 1 & 2 & 3 & 4 \\
\hline Комплексная оценка (итого) & От 5 до 7 & От 8 до 12 & От 11 до 17 & От 18 до 20 \\
\hline
\end{tabular}

Другой способ комплексной оценки эффективности - интегральный предложен в работах сестёр Боровковых [23] и Гранкина А. А. [23]. 
Согласно подходу сестёр Боровковых:

$I_{\text {эсмр }}=\frac{\sum_{i=1}^{5}\left(I_{i} \times d_{i}\right)}{n}$,

где $\quad I_{\text {эсмр }}-$ интегральный показатель оценки эффективности СУР;

$I_{i}$ - интегральный показатель эффективности реализации -й цели СУР;

$d_{i}$ - значимость -й цели СУР.

При этом существует всего 5 целей стратегии управления рисками, эффективность реализации которых оценивается по следующим формулам:

$I_{1}=\sqrt[7]{K_{1} \times K_{21} \times K_{25} \times K_{26} \times K_{27} \times K_{28} \times K_{38}}$,

где $I_{1}$ - обеспечение сбалансированности рисков предприятия;

$K_{1}$ - коэффициент финансовой устойчивости;

$K_{21}$ - уровень затрат на разработку управленческого регламента СУР;

$K_{25}$ - рискоёмкость;

$K_{26}$ - уровень управляемости рисками на предприятии;

$K_{27}$ - уровень полноты информации;

$K_{28}$ - уровень стабильности СУР;

$K_{38}$ - доля инновационных технологий СУР.

$I_{2}=\sqrt[7]{K_{7} \times K_{19} \times K_{29} \times K_{32} \times K_{34} \times K_{47} \times K_{49}}$,

где $I_{2}-$ повышение комплексной безопасности предприятия;

$K_{7}$ - коэффициент текущей ликвидности;

$K_{19}$ - уровень квалификации кадров;

$K_{29}$ - коэффициент риска;

$K_{32}$ - эффективность СУР на национальном уровне;

$K_{34}$ - уровень обеспечения сохранности ТМЦ;

$K_{47}$ - уровень оперативности прохождения информации;

$K_{49}-$ доля штрафов в прибыли.

$I_{3}=\sqrt[7]{K_{2} \times K_{3} \times K_{4} \times K_{9} \times K_{17} \times K_{33} \times K_{41}}$,

где $I_{3}$ - рост эффективности деятельности предприятия;

$K_{2}$ - рентабельность использования торговых площадей;

$K_{3}$ - рентабельность продаж;

$K_{4}$ - товарооборачиваемость;

$K_{9}$ - коэффициент оборачиваемости кредиторской задолженности;

$K_{17}$ - эффективность использования трудовых ресурсов;

$K_{33}$ - эффективность использования основных фондов;

$K_{41}$ - эффективность использования затрат. 
$I_{4}=\sqrt[7]{K_{20} \times K_{44} \times K_{50} \times K_{51} \times K_{53} \times K_{54} \times K_{56}}$,

где $I_{4}-$ повышение согласованности и эффективности взаимодействия;

$K_{20}$ - уровень координации;

$K_{44}-$ уровень организационной культуры;

$K_{50}$ - уровень удовлетворённости сотрудников;

$K_{51}$ - уровень удовлетворённости потребителей;

$K_{53}$ - уровень удовлетворённости собственников;

$K_{54}$ - уровень удовлетворённости контрагентов;

$K_{56}-$ уровень удовлетворённости государства.

$I_{5}=\sqrt[7]{K_{10} \times K_{23} \times K_{31} \times K_{35} \times K_{36} \times K_{39} \times K_{43}}$,

где $I_{5}-$ рост конкурентоспособности предприятия;

$K_{10}$ - коэффициент сохранения постоянных потребителей;

$K_{23}$ - коэффициент повышения профессионального уровня сотрудников;

$K_{31}$ - уровень внедрения риск-менеджмента;

$K_{35}$ - коэффициент обновления основных фондов;

$K_{36}$ - коэффициент внедрения информационных технологий;

$K_{39}$ - коэффициент инновационной активности;

$K_{43}$ - уровень доступности услуг.

Методика, предложенная Гранкиным А. А., отлична от методики сестёр Боровковых и находит своё применение только в рамках банковской системы:

$R=\frac{\sum_{i=1}^{5} K_{i}}{5}$,

где $\quad R-$ интегральный показатель эффективности СУР предприятия;

$K_{i}$ - внутренний коэффициент интегрального показателя.

По его методике также существует всего 5 внутренних коэффициентов:

$K_{1}=\frac{H_{1}-10}{10}$,

где $K_{1}$ - степень выполнения норматива $H_{1}$;

$H_{1}$ - норматив достаточности собственных средств.

$K_{2}=\frac{H_{2}-15}{15}$,

где $K_{2}$ - степень выполнения норматива $\mathrm{H}_{2}$;

$\mathrm{H}_{2}$ - норматив мгновенной ликвидности.

$K_{3}=\frac{H_{3}-50}{50}$,

где $K_{3}$ - степень выполнения норматива $H_{3}$;

$\mathrm{H}_{3}$ - норматив текущей ликвидности. 


$$
K_{4}=\frac{25-H_{6}}{25}
$$

где $K_{4}$ - степень выполнения норматива $H_{6}$;

$H_{6}$ - норматив максимального размера риска на одного заёмщика.

$K_{5}=\frac{800-H_{7}}{800}$,

где $K_{5}-$ степень выполнения норматива $H_{7}$;

$H_{7}$ - норматив максимального размера крупных кредитных рисков.

Необходимо отметить, что в отличие от рассмотренных первоначально рекомендаций Р 50.1.093-2014 изученные способы оценки эффективности системы риск-менеджмента большей частью носят не прогнозный, а фактический характер [25]. Таким образом, исследователи в основном предлагают оценку уже состоявших методов управления рисками на предприятии. В связи с чем в последнее время всё большую популярность набирают искусственные нейронные сети, благодаря которым риск-менеджеры открывают для себя новые эффективные (чёткие и удобные в использовании) способы управления рисками. Также необходимо помнить, что по Парето 60\% эффективности зависит непосредственно от внедрения риск-ориентированной культуры и лишь $40 \%$ - от выполнения всех процедур [26].

\section{Список литературы}

1. Блэк Дж. Экономика. Толковый словарь: Общая ред. И. М. Осадчая [Текст] // М.: «ИНФРА-М», Издательство «Весь Мир. - 2000.

2. Крикливец, А. А., Сухомыро П. С. Понятие эффективности в экономической науке [Текст] // Молодой ученый. - 2019. - № 2 (240). C. 237-239.

3. Кочетков В. В., Ратушняк Е. С. Показатели оценки эффективности управления [Текст] // Управление экономическими системами. - 2017. - №. 3 (97).

4. Р 50.1.093-2014. Менеджмент риска. Принципы оценки эффективности воздействий на риск [Электронный ресурс] // Рекомендации по стандартизации. Режим доступа: http://docs.cntd.ru/document/1200120079.

5. Анесянц С. А., Сергиенко И. А., Гусаков И. Ю. Оценка эффективности процессов по управлению рисками предприятия [Текст] // Заметки учёного. 2018. - №. 1. - С. 29-32.

6. Барашьян В. Ю. Оценка эффективности риск-менеджмента как инструмента обеспечения финансовой безопасности компании [Текст] // Лучшая 
научно-исследовательская работа 2017: экономика, политика, социология и право. $-2017 .-$ C. $40-44$.

7. Гостенина В. В., Духанина Е. В. К вопросу об оценке эффективности системы риск-менеджмента [Текст] // Территория инноваций. - 2017. - №. 11. - С. 37.

8. Демиденко Д. С., Филотенкова В. В. Матрица рисков как способ определения эффективности применения систем риск-менеджмента [Текст] // Неделя науки СПбПУ. - 2016. - С. 410-413.

9. Енина Е. П., Менжулин Р. В. Методика оценки эффективности системы риск-менеджмента на основе шансо-риска в банковских системах [Текст] // Экономинфо. - 2018. - №. 1.

10. Корниенко О. Ю., Макарова В. А. Актуальные вопросы оценки эффективности корпоративного риск менеджмента: Монография [Текст] // Изд. 2е, дополненное. - СПб.: Изд-во Политехнического университета, 2015. - 279 с.

11. Макарова В. А. Анализ и оценка экономической эффективности рискменеджмента [Текст] // Стратегические решения и риск-менеджмент. - 2015. № 3 .

12. Макарова В. А. Влияние эффективности ERM на ставку дисконтирования [Текст] // Экономика. Бизнеса. Банки. - 2016. - № 3. - С. 39-56.

13. Михеев П. С., Горлова Д. Эффективное использование риск-аппетита в компании [Текст] // Наука. Исследования. Практика. - 2020. - С. 211-215.

14. Муравьева Н. Н., Блинова Т. К. Обоснование критериев эффективности управления финансовыми рисками в коммерческих организациях [Текст] // Экономика и бизнес: теория и практика. - 2015. - №. 1.

15. Пальбин A. В. Подходы к повышению эффективности рискменеджмента предпринимательских структур [Текст] // Путеводитель предпринимателя. - 2017. - №. 34. - С. 194-204.

16. Филотенкова В. В. Эффективность систем риск-менеджмента и её оценка [Текст] // Современная экономика социальные вызовы и финансовые проблемы XXI века. - 2017. - С. 567-572.

17. Рубин А. Г., Рубин Д. А., Рубина О. Ю. Системный подход как инструмент оценки эффективности менеджмента предприятия [Текст] // Вестник Челябинского государственного университета. - 2018. - №. 7 (417).

18. Оганисян Л. А. Принципы, подходы и организационные модели построения эффективной системы риск-менеджмента в компании [Текст] // Инновационная наука в глобализующемся мире. - 2017. - №. 1. - С. 102-106. 
19. COSO. Enterprise Risk Management - Integrating with Strategy and Performance (2017) [Электронный ресурс]. - Режим доступа: https://www.coso.org /Documents/2017-COSO-ERM-Integrating-with-Strategy-and-Performance-ExecutiveSummary.pdf.

20. Руденко И. В. Оценка эффективности функционирования системы рискменеджмента на предприятии [Текст] // Инновационная наука. - 2015. - №. 8. - С. 56.

21. Новиков А. А., Донцова Л. В. Концептуальные основы модели оценки эффективности риск-менеджмента на базе системы KPI [Текст] // Цифровое будущее инновационной экономики России. - 2018. - С. 191-197.

22. Сафонова М. Ф., Резниченко Д. С. Оценка эффективности управления налоговыми рисками [Текст] // Инновационное развитие экономики. - 2017. № $1 .-$ С. $88-98$.

23. Боровкова В. А., Боровкова В. А. Методологические аспекты оценки стратегии менеджмента риска организации [Текст] // Экономика: вчера, сегодня, завтра. - 2018. - Т. 8. - №. 3А. - C. 27-38.

24. Силкина Н. Г., Гранкин А. А. Оценка эффективности риск-менеджмента коммерческого банка с использованием интегрального показателя [Текст] // Вопросы науки: теоретический и практический аспекты. - 2017. - С. 18-20.

25. Кочетова Т. С. Построение эффективного риск-менеджмента для российских компаний на примере ПАО" Аэрофлот" [Текст] // От научных идей к стратегии бизнес-развития. - 2018. - С. 217-224.

26. Епишкин И. А., Несова Т. А. Формула эффективности российского риск-менеджмента (на примере ОАО «РЖД») [Текст] // Актуальные проблемы управления экономикой и финансами транспортных компаний. $-2016 .-$ C. 31-34.

( Е.Д. Блинова, 2020 